\title{
Risk factors for an anxiety disorder comorbidity among Thai patients with bipolar disorder: results from the Thai Bipolar Disorder Registry
}

This article was published in the following Dove Press journal:

Neuropsychiatric Disease and Treatment

15 May 2014

Number of times this article has been viewed

\begin{abstract}
Suchat Paholpak'
Ronnachai Kongsakon ${ }^{2}$

Wasana Pattanakumjorn ${ }^{3}$

Roongsang Kanokvut ${ }^{4}$

Wiroj Wongsuriyadech ${ }^{5}$

Manit Srisurapanont ${ }^{6}$
\end{abstract}

On behalf of the Thai Bipolar Disorder Registry Study Group

'Department of Psychiatry, Faculty of Medicine, Khon Kaen University, Khon Kaen, ${ }^{2}$ Department of Psychiatry, Faculty of Medicine Ramathibodi Hospital, Mahidol University, Bangkok, ${ }^{3}$ Department of Psychiatry, Ratchaburi Hospital, Ratchaburi, ${ }^{4}$ Department of Psychiatry, Buddhachinaraj Hospital, Phitsanulok, ${ }^{5}$ Department of Psychiatry, Udonthani Hospital, Udonthani, ${ }^{6}$ Department of Psychiatry, Faculty of Medicine, Chiang Mai University, Chiang Mai, Thailand

\section{Video abstract}

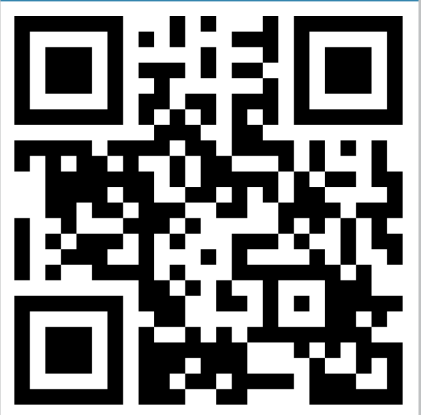

Point your SmartPhone at the code above. If you have a QR code reader the video abstract will appear. Or use: http://dvpr.es/lgdEOeN

Correspondence: Suchat Paholpak Department of Psychiatry, Faculty of Medicine, Khon Kaen University, Khon Kaen 40002, Thailand

Tel +668 I 6610674

$\mathrm{Fax}+6643348484$

Email suchat_p@kku.ac.th
Background: The aim of the study was to determine in a clinical setting the risk factors for current anxiety disorder (AD) comorbidity among Thai patients with bipolar disorder (BD), being treated under the Thai Bipolar Disorder Registry Project (TBDR).

Methods: The TBDR was a multisite naturalistic study conducted at 24 psychiatric units (ie, at university, provincial mental, and government general hospitals) between February 2009 and January 2011. Participants were in- or out-patients over 18 years of age who were diagnosed with BD according to the Diagnostic and Statistical Manual of Mental Disorders, Fourth Edition. Instruments used in this study included the Thai Mini International Neuropsychiatric Interview version 5; Thai Montgomery-Åsberg Depression Rating Scale (MADRS); Thai Young Mania Rating Scale; Clinical Global Impression of Bipolar Disorder-Severity (CGI-BP-S), CGI-BP-S-mania, CGI-BPS-depression, and CGI-BP-S-overall BP illness; and the Thai SF-36 quality of life questionnaire. Results: Among the 424 BD patients, 404 (95.3\%) had BD type I. The respective mean \pm standard deviation of age of onset of mood disturbance, first diagnosis of $\mathrm{BD}$, and first treatment of $\mathrm{BD}$ was $32.0 \pm 11.9,36.1 \pm 12.2$, and $36.2 \pm 12.2$ years. The duration of illness was $10.7 \pm 9.0$ years. Fifty-three (12.5\%) of the 424 participants had a current AD while $38(9 \%)$ had a substance use disorder (SUD). The univariate analysis revealed 13 significant risks for current AD comorbidity, which the multivariate analysis narrowed to age at first diagnosis of $\mathrm{BD}$ (odds ratio $=0.95, P<0.01$ ), family history of SUD (odds ratio $=2.18, P=0.02$ ), and having a higher current MADRS score (odds ratio $=1.11, P<0.01$ ).

Conclusion: A diagnosis of $\mathrm{AD}$ comorbid with $\mathrm{BD}$ is suggested by early-age onset of $\mathrm{BD}$ together with a higher MADRS score and a family history of SUD. The likelihood of AD comorbidity decreases by $5 \%$ with each passing year; early-age onset of BD is a risk while later age onset is protective. Our results underscore how SUD within the family significantly contributes to the risk of an $\mathrm{AD}$ comorbidity.

Keywords: bipolar disorders, risk, protect, anxiety, comorbid, Thai

\section{Introduction}

Bipolar disorder (BD) is a highly prevalent mental illness affecting $2.4 \%$ of the worldwide population. ${ }^{1}$ In Thailand, the prevalence of BD as assessed in 2003 using the Thai Mini International Neuropsychiatric Interview (MINI) was $0.65 \%{ }^{2}$ The disorder is characterized by mood episodes comprising mania alternating with depression. The clinical course of BD is chronic and typically spans an entire segment in the life of a patient. ${ }^{3}$ The chronicity of $\mathrm{BD}$ results in a high rate of recurrence and a number of psychiatric or medical comorbidities, including anxiety disorder (AD), substance use disorder (SUD), attention-deficit/hyperactivity disorders, personality disorders, migraine, hypothyroidism, and/or diabetes. ${ }^{4}$ 
$\mathrm{AD}$ is a common - and perhaps the most common comorbidity ${ }^{5}$ in patients with $\mathrm{BD}$ during either manic, depressive episodes or even during euthymic state. ${ }^{6,7} \mathrm{~A}$ large cohort study described a higher incidence of comorbid $\mathrm{AD}$ in $\mathrm{BD}$ patients than in the general population. ${ }^{8,9}$ In a prospective follow-up, BD patients with a comorbid social phobia have a longer mood duration and greater severity of illness than those without. ${ }^{10}$ Comorbid obsessive compulsive disorder (OCD) has a history of a shorter period of euthymia. ${ }^{11}$ Compared with BD alone, patients with comorbid $\mathrm{AD}$ have a higher burden of $\mathrm{BD}$ symptoms, greater severity, and sometimes manifestation of a different clinical pattern than $\mathrm{BD}$ alone. ${ }^{8} \mathrm{~A}$ greater number of attempted suicides are also associated with OCD, panic disorder (PD), and social phobia comorbidity. ${ }^{9}$ BD patients with comorbid AD need more complex clinical management and treatment because of the prolonged severity of disease burden, which in turn causes more problems with sleep and impairs work and social functioning. ${ }^{8}$ This population does not, however, usually receive appropriate treatment. ${ }^{9,11}$

The risk factors for having comorbid suicidality ${ }^{12}$ and $\mathrm{SUD}^{13}$ in BD have been widely studied. Antypa et al reported that the strongest risk factor for a future suicide event is a prior history of suicide attempts, the other potential risk factors includes younger age, personality disorder traits, and a high percentage of days spent depressed. ${ }^{14}$ Risk factors for SUD in BD are lifetime oppositional defiant disorder, any lifetime $\mathrm{AD}$, adolescent-onset $\mathrm{BD}$, and suicide attempt(s). ${ }^{15}$

To date, only a few reports have been conducted on the risk factors for comorbid AD in $\mathrm{BD}$. Using the Diagnostic Interview for Genetic Studies in patients with either bipolar or schizoaffective disorder, Saunders et al found that a) being younger at onset of $\mathrm{BD}$ is a risk factor for OCD comorbidity for both sexes, and b) experiencing more antidepressant trials is a risk factor for $\mathrm{OCD}, \mathrm{PD}$, and specific phobia in both sexes. ${ }^{8} \mathrm{~A}$ community mental health survey in Canada revealed a comorbid mood and $\mathrm{AD}$ was more likely for those a) being young, unmarried, and not fully employed, b) having a medical condition, c) experiencing greater than normal levels of stress, d) rating oneself poorer for mental health, and e) being dissatisfied with life. ${ }^{16}$ The aforementioned studies, ${ }^{8,16}$ however, were done in particular groups of patients or individuals and mostly in Western countries. We wanted to investigate the similarities and differences in clinical risk factors for current $\mathrm{AD}$ in comorbidity with $\mathrm{BD}$ in a large sample of patients with BD in a naturalistic clinical Asian setting.
The Thai Bipolar Disorder Registry Project (TBDR) was established nationwide to observe the clinical course of Thai patients with BD over a 1-year period. ${ }^{17}$ The Registry also collected data regarding clinical parameters, including current comorbidities at baseline. The baseline data were analyzed for risk factors associated with the current ADs comorbidity in Thai patients with BD. The objective of the study was to examine the demographics and clinical characteristics of, and risk factors associated with, current ADs in comorbidity with $\mathrm{BD}$ in Thai patients.

\section{Materials and methods}

The TBDR was a 1-year multisite, prospective, naturalistic clinical study, conducted between February 2009 and January 2011 in Thailand. The TBDR comprised 24 psychiatric servicing units at various hospitals (ie, university, provincial general, and mental). The primary objective was to characterize the course of BD illness among a sample of Thai patients. The study did not involve any clinical management of the participants. The reader can find details in a recent article. ${ }^{17}$ The institutional review board at each site approved the protocol.

\section{Participants}

Participants in this study were the bipolar I and II patients attending psychiatric services during the study period, either as out-patients or in-patients at any of the investigation sites. Patients with BD in the study had to meet the following inclusion criteria: a) in- or out-patient diagnosed with BD according to the Diagnostic and Statistical Manual of Mental Disorders, Fourth Edition (DSM-IV), b) over 18 years of age, c) receiving treatment for $\mathrm{BD}$ at one of the research sites during the study period, d) literate in Thai, e) able to make return visits to the hospital every 2 months, and f) able to provide informed written consent after having the details of the study fully explained.

BD patients with any of the following criteria were excluded: a) participating in other research, b) having difficulty traveling, and c) not able to give informed consent.

\section{Assessment}

Patients who fulfilled the study criteria were invited to participate in the study. All participants were assessed at baseline (visit 1$)$ and every $2( \pm 1)$ months for 12 months (visit 7). Data collected at baseline included a) demographic details, b) history of BD illness, c) current status of BD (ie, any one of the following: recovered, recovering, roughening, continued 
symptomatic, major depressive episode, manic episode, hypomanic episode, and/or mixed episode), d) concurrent comorbid psychiatric (any AD and SUD) and nonpsychiatric medical disorder(s)/disease(s), e) current suicidal risk, f) current psychiatric treatment, g) health status (including vital signs, physical examinations, and clinical laboratory tests), and h) quality of life.

The Thai MINI was used to establish the DSM-IV diagnosis of BD I and BD II, current BD illness status, concurrent comorbid psychiatric disorder, and current suicidal risk. The Thai MINI is a structured diagnostic psychiatric interview for the DSM-IV and the International Classification of Diseases-10, which has been translated into Thai. The validity of the Thai MINI has been tested against interviews conducted by Thai Medical Council Board-certified psychiatrists. The MINI has several modules, but the ones chosen for this study are specifically used for diagnosing major depressive episode, (hypo)manic, ADs (generalized AD, OCD, phobic disorder and/or PD), SUD (alcohol and nonalcohol use disorder), and suicide risk.

The respective time-frames required when using the MINI to make a psychiatric diagnosis of a) major depressive episode, b) (hypo)manic episode, c) PD, agoraphobia, social phobia, OCD, d) generalized AD, e) alcohol and nonalcohol psychoactive SUD and f) current suicidal risk are 2 weeks, 1 week, 1 month, 6 months, 12 months, and 1 month.

Udomratn and Kittirattanapaiboon, in 2004, evaluated the interrater reliability, sensitivity, and specificity of the Thai MINI for various entities. The respective interrater reliability (Cohen's $\kappa$ ), sensitivity, and specificity of the module for major depressive episode was $0.84,0.98$, and 0.94; (hypo)manic episode $0.78,0.89$, and 0.94; PD 1.0, 1.0, and 1.0; PD with agoraphobia $0.48,0.60$, and 0.98 ; PD without agoraphobia 0.74 , 0.60 , and 1.0 ; agoraphobia $0.31,0.50$, and 0.94 ; social phobia $0.35,0.43$, and 0.96 ; OCD $0.32,0.44$, and 0.95 ; generalized AD $0.89,1.00$, and 0.97 ; alcohol dependence $0.74,0.92$, and 0.93 ; alcohol abuse $0.40,0.41$, and 0.95 ; substance dependence 0.92 , 0.95 , and 0.99; substance abuse incomputable, incomputable, and 0.99 ; and suicidal risk $0.86,0.96$, and $0.91 .^{18}$

The severity of symptoms and syndrome of (hypo)manic episode were measured using the Thai Young Mania Rating Scale (interrater reliability [Pearson's correlation] 0.87, Cronbach's $\alpha$ coefficient 0.89). ${ }^{19}$ Major depressive episodes were measured using the Thai Montgomery-Åsberg Depression Rating Scale (MADRS) (interrater reliability [Cohen's $\kappa] ~ 0.78$, Cronbach's $\alpha$ coefficient 0.80$).{ }^{20}$ The overall severity of the current mood status was evaluated using the Clinical Global Impression of
Bipolar Disorder-Severity (CGI-BP-S): CGI-BP-S-mania, CGI-BP-S-depression and CGI-BP-S-overall BP illness. ${ }^{21}$ All of these measures were administered by MINI-trained psychiatrists with experience in clinical studies involving BD patients. Quality of life was measured using the Thai version of the self-rating SF-36 questionnaire (test-retest reliability [Pearson's correlation] 0.6, Cronbach's $\alpha$ coefficient 0.92). ${ }^{22}$ The SF-36 is a self-rating questionnaire comprising eight domains with 100 marks for each domain, including mental health, general health, bodily pain, physical functioning, role physical, role emotional, vitality, and social functioning.

In order to comply with the objectives of the current study, only data at baseline were used for analysis. The institutional review board at each site approved the protocol. Patients were asked to give informed, written consent before participating in the study.

\section{Statistical analysis}

The main objective of the study was analyzed with descriptive statistics exclusively. Total values and percentages were used for the categorical variables while means with standard deviations (SD) were used for the quantitative variables. A comparative analysis was done using bivariate and multivariate analyses. The Student's $t$-test and the $\chi^{2}$-test were used for the bivariate analyses while logistical regression was used for the multivariate analyses. A value $P \leq 0.05$ was considered statistically significant.

\section{Results}

The present study recruited 424 patients with BD, of whom 404 (95.3\%) had BD type I.

\section{Demographic characteristics}

The patients averaged $42.7 \pm 12.3$ years of age. Most $(258 ; 60.8 \%)$ were female, $211(49.9 \%)$ were married, 147 (34.8\%) were single, and the remaining 57 patients $(15.3 \%)$ were divorced or widowed. The majority $(276 ; 65.3 \%)$ had less than 12 years of education.

\section{Family history}

One hundred and thirty-two (31.2\%) of the 423 participants had some type of psychiatric disorder and four of the patients $(3.0 \%)$ had SUD in the family.

\section{Prevalence of comorbidity}

Fifty-three (12.5\%) of the 424 BD participants had some kind of current AD: 18 (34.0\%) generalized AD, 15 (28.3\%) 
OCD, 13 (24.5\%) agoraphobia, nine (17.0\%) social phobia, and seven (13.2\%) PD. Thirty-eight (9\%) patients had SUD of some kind (alcohol or nonalcohol).

\section{Course of illness}

The respective age at onset of mood disturbance, first diagnosis of BD, first treatment of BD, and duration of BD illness was $32.0 \pm 11.9,36.1 \pm 12.2,36.2 \pm 12.2$, and $10.7 \pm 9.0$ years.

\section{Clinical features}

At baseline, $255(60.1 \%)$ patients were in recovery, 48 (11.3\%) were recovering, three $(0.7 \%)$ were roughening, $26(6.1 \%)$ continued symptomatic, 30 (7.1\%) depressed, 29 (6.8\%) manic, 20 (4.7\%) mixed, and 13 (3.2\%) hypomanic. Eleven $(2.6 \%)$ and nine $(2.1 \%)$ of the patients had moderate and high suicidal risk, respectively.

\section{Quality of life}

Scores for the SF-36 Thai version of the whole sample at baseline were a) physical functioning $81.8 \pm 20.0$, b) role physical $70.2 \pm 40.2$, c) bodily pain $76.4 \pm 23.3$, d) general health $58.1 \pm 22.8$, e) vitality $60.4 \pm 16.3, \mathrm{f}$ ) social functioning $77.3 \pm 24.1, \mathrm{~g}$ ) role emotional $63.9 \pm 42.1$, and $\mathrm{h}$ ) mental health $70.0 \pm 18.3$.

\section{Univariate analysis}

Clinical parameters (variables) were analyzed one by one for any association they might have with AD comorbidity. None of the demographic data had any statistically significant association with comorbid $A D$, including subtype of BD (BD I or BD II, $P=0.47)$, sex $(P=0.10)$, marital status $(P=0.32)$, and educational level $(P=0.57)$. Family history of psychiatric illness and SUD also did not have any statistically significant association with the comorbid $\operatorname{AD}(P=0.26$ and $P=0.37$, respectively). Some variables regarding the course of illness did, however, have positive associations, including earlier age onset of mood disturbance $(P=0.02)$, earlier age of BD onset $(P=0.04)$, earlier age at the first treatment for BD $(P=0.05)$, mixed polarity at the first mood episode $(P \leq 0.01)$, and history of rapid cycling $(P=0.05)$.

Variables at baseline identified as having a positive association with comorbid AD included current younger age $(P=0.008)$, depressive polarity of the current mood episode $(P<0.01)$, high suicidality $(P<0.01)$, and higher score in the clinical psychometric scale (ie, Thai Young Mania Rating Scale, Thai MADRS, CGI-BP-S-mania, CGI-BP-Sdepression, and CGI-BP-S-overall BP illness; $P \leq 0.05$ ). BD patients with comorbid $\mathrm{AD}$, compared with those without the comorbidity, had a lower quality of life as assessed by the SF-36 in almost all domains $(P<0.01$ for every domain, with the exception of $P=0.03$ for the domain of physical functioning). The presence of comorbid SUD was not significantly associated with AD comorbidity $(P=0.45)$ (Table 1$)$.

\section{Multivariate analysis}

Interactions among variables and AD comorbidity were inferred from the regression model of the multivariate analysis. Variables entered into the model included all those with a $P \leq 0.2$ from the univariate analyses. SUD, whether present in the family or in the patient, even if the $P>0.2$, was also entered into the model of analysis because of its theoretical association with BD. ${ }^{23}$ In the final step of the regression analysis, the variables that still had a statistical significant positive association with $\mathrm{AD}$ comorbidity were age at onset of $\mathrm{BD}$ (odds ratio $=0.95,95 \%$ confidence interval $[\mathrm{CI}]$ $=0.93-0.97, P<0.01$ ), SUD in the patient's family (odds ratio $=2.18,95 \% \mathrm{CI}=1.11-4.27, P=0.02)$, and a higher MADRS (odds ratio $=1.10,95 \% \mathrm{CI}=1.06-1.15, P<0.01$ ) (Table 2 ).

\section{Discussion}

This is the first study on the risk factors for comorbid AD among patients with BD in Thailand. We utilized univariate and multivariate analyses to identify clinical parameters that would be a risk factor for AD comorbidity. One parameter identified was the age at onset of BD. Due to an odds ratio of 0.95 , with a $95 \%$ CI of $0.93-0.97$, this risk could be interpreted in two ways: 1) early onset could be a risk factor and 2) later onset could be a protective factor. Since the odds ratio was 0.95 , it means that for every 1 -year increment of the onset of $\mathrm{BD}$, there would be a $5 \%$ reduction in the chance of having AD comorbidity.

Our finding that early-age onset of BD is a risk factor for AD comorbidity agrees with the finding of others including Etain et $\mathrm{al}^{24}$ and Azorin et al. ${ }^{25}$ Besides its association with $\mathrm{AD}$ comorbidity, early-age onset of $\mathrm{BD}$ is also found to be in association with comorbid SUD. ${ }^{25}$ Our results, therefore, make an important contribution to the knowledge of onset risk, as we observed that later onset of BD was associated with a reduced risk of $\mathrm{AD}$ comorbidity.

In another facet, children and adolescents exposed to SUD at home encountered problems with respect to attachment, nurturing, socialization, economic hardship, breaking the law, emotional distress, and violence. ${ }^{26}$ These children also have an increased risk for internalizing problems such as anxiety, depression, and substance abuse. ${ }^{26,27}$ The whole family and each family member in this situation are affected by the 
Table I Bipolar disorder illness course and current clinical characteristics in association with comorbid anxiety disorder

\begin{tabular}{|c|c|c|c|c|}
\hline & & \multicolumn{3}{|c|}{ Comorbid anxiety disorder } \\
\hline & & $\begin{array}{l}\text { Yes } \\
(N=53)\end{array}$ & $\begin{array}{l}\text { No } \\
(N=37 I)\end{array}$ & $P$-value \\
\hline \multicolumn{5}{|l|}{ Family history } \\
\hline Presence of psychiatric disorder & $\mathrm{N}=423$ & & & \\
\hline Yes & 132 & $14(10.6 \%)$ & II 8 (89.4\%) & 0.26 \\
\hline No & 291 & 39 (13.4\%) & $252(86.6 \%)$ & \\
\hline Presence of substance use disorder & $\mathrm{N}=132$ & & & \\
\hline Yes & 4 & I (25\%) & $3(75 \%)$ & 0.37 \\
\hline No & 128 & $13(10.2 \%)$ & II 5 (89.8\%) & \\
\hline \multicolumn{5}{|l|}{ Illness course of BD } \\
\hline Age (year) mean $\pm S D$ & $\mathrm{~N}=424$ & & & \\
\hline I. Age onset of mood disturbance & $32.0 \pm 11.9$ & $28.5 \pm 10.8$ & $32.5 \pm 12.0$ & 0.02 \\
\hline 2. Age onset of $B D$ & $36.1 \pm 12.2$ & $32.9 \pm 11.2$ & $36.6 \pm 12.3$ & 0.04 \\
\hline 3. Age at the first treatment for $B D$ & $36.2 \pm 12.2$ & $33.1 \pm 11.3$ & $36.6 \pm 12.3$ & 0.05 \\
\hline 4. Duration of BD & $10.7 \pm 9.0$ & $9.8 \pm 8.5$ & $10.8 \pm 9.1$ & 0.42 \\
\hline Polarity of the first lifetime mood episode & $\mathrm{N}$ by subtype & & & \\
\hline I. Mixed & 28 & $10(35.7 \%)$ & $18(64.3 \%)$ & $<0.01$ \\
\hline 2. Depressed & 109 & $17(15.6 \%)$ & $92(84.6 \%)$ & \\
\hline 3. Manic/hypomanic & 274 & $26(9.5 \%)$ & $248(90.5 \%)$ & \\
\hline 4. Unknown & 13 & $0(0.0 \%)$ & $13(100.0 \%)$ & \\
\hline Current clinical status (baseline) & $N=424$ & & & \\
\hline The current age (years) mean \pm SD & $42.7 \pm 12.3$ & $38.6 \pm 10.9$ & $43.29 \pm 12.4$ & 0.008 \\
\hline Pole of the current mood episode & $\mathrm{N}$ by subtype & & & \\
\hline I. Recovered & 255 & $20(8.5 \%)$ & 235 (9l.5\%) & $<0.01$ \\
\hline 2. Recovering & 48 & 7 (I7.1\%) & $4 \mathrm{l}(82.9 \%)$ & \\
\hline 3. Roughening & 3 & $0(0.0 \%)$ & $3(100.0 \%)$ & \\
\hline 4. Continued symptomatic & 26 & I (4.0\%) & $25(96.0 \%)$ & \\
\hline 5. Depressed & 30 & $13(76.5 \%)$ & $17(23.5 \%)$ & \\
\hline 6. Mixed & 20 & $6(42.9 \%)$ & 14 (57.1\%) & \\
\hline 7. Manic & 29 & $4(16.0 \%)$ & $25(84.0 \%)$ & \\
\hline 8. Hypomanic & 13 & $2(18.2 \%)$ & II (9I.8\%) & \\
\hline Psychometric scales mean \pm SD & $\mathrm{N}=424$ & & & \\
\hline I. Thai YMRS & $3.8 \pm 5.6$ & $5.3 \pm 5.5$ & $3.6 \pm 5.6$ & 0.05 \\
\hline 2. Thai MADRS & $4.8 \pm 6.6$ & $10.4 \pm 7.8$ & $4.0 \pm 6.0$ & $<0.01$ \\
\hline 3. CGI-BP-S-mania & $1.7 \pm 1.2$ & $2.0 \pm 1.4$ & $1.6 \pm 1.1$ & 0.04 \\
\hline 4. CGI-BP-S-depression & $1.5 \pm 1.1$ & $2.4 \pm 1.5$ & $1.4 \pm 0.9$ & $<0.01$ \\
\hline 5. CGI-BP-S-overall BP illness & $1.9 \pm 1.3$ & $2.5 \pm 1.4$ & $1.7 \pm 1.2$ & $<0.01$ \\
\hline Suicidal risk & $\mathrm{N}=424$ & & & \\
\hline I. No & 314 & $30(9.6 \%)$ & 284 (90.4\%) & $<0.01$ \\
\hline 2. Low & 90 & $16(17.8 \%)$ & $74(82.2 \%)$ & \\
\hline 3. Moderate & 11 & $4(36.4 \%)$ & $7(63.6 \%)$ & \\
\hline 4. High & 9 & $3(33.3 \%)$ & $6(66.7 \%)$ & \\
\hline Current substance use disorder & $\mathrm{N}=424$ & & & \\
\hline I. Positive & 38 & $6(15.8 \%)$ & $32(84.2 \%)$ & 0.45 \\
\hline 2. Negative & 386 & $47(12.2 \%)$ & $339(87.8 \%)$ & \\
\hline Quality of life SF-36 Thai version mean \pm SD & $\mathrm{N}=424$ & & & \\
\hline I. Physical functioning & $81.8 \pm 20.0$ & $76.3 \pm 21.0$ & $82.6 \pm 19.7$ & 0.03 \\
\hline 2. Role physical & $70.2 \pm 40.2$ & $38.7 \pm 39.4$ & $74.8 \pm 38.3$ & $<0.01$ \\
\hline 3. Bodily pain & $76.4 \pm 23.3$ & $60.2 \pm 26.7$ & $78.8 \pm 22.3$ & $<0.01$ \\
\hline 4. General health & $58.1 \pm 22.8$ & $60.9 \pm 21.6$ & $38.2 \pm 21.1$ & $<0.01$ \\
\hline 5. Vitality & $60.4 \pm 16.3$ & $46.1 \pm 17.9$ & $62.3 \pm 15.0$ & $<0.01$ \\
\hline 6. Social functioning & $77.3 \pm 24.1$ & $55.7 \pm 27.8$ & $80.4 \pm 21.9$ & $<0.01$ \\
\hline 7. Role emotional & $63.9 \pm 42.1$ & $33.3 \pm 38.1$ & $68.3 \pm 40.9$ & $<0.01$ \\
\hline 8. Mental health & $70.0 \pm 18.3$ & $72.2 \pm 17.2$ & $53.7 \pm 17.3$ & $<0.01$ \\
\hline
\end{tabular}

Abbreviations: BD, bipolar disorder; CGI-BP-S, Clinical Global Impression Severity of Illness Scale for Bipolar Disorder; MADRS, Montgomery-Åsberg Depression Rating Scale; SD, standard deviation; YMRS, Young Mania Rating Scale. 
Table 2 Multivariate analysis of factors associated with comorbidity

\begin{tabular}{lccccc}
\hline Factor & Wald & df & $\begin{array}{l}\text { Odds } \\
\text { ratio }\end{array}$ & $\mathbf{9 5 \%} \mathbf{C l}$ & P-value \\
\hline $\begin{array}{l}\text { Substance use } \\
\text { disorder in the family }\end{array}$ & 5.14 & $\mathrm{I}$ & 2.18 & $\mathrm{I} .1 \mathrm{I}-4.27$ & 0.02 \\
MADRS score & 25.24 & $\mathrm{I}$ & $\mathrm{I} .10$ & $\mathrm{I} .06-\mathrm{I} .15$ & $<0.0 \mathrm{I}$ \\
Age of onset of BD & 27.07 & $\mathrm{I}$ & 0.95 & $0.93-0.97$ & $<0.0 \mathrm{I}$ \\
\hline
\end{tabular}

Notes: $R^{2}$ is $0.228 ;-2$ log likelihood is 73.24 ; Hosmer-Lemeshow test's $P=0.656$. Abbreviations: MADRS, Montgomery-Åsberg Depression Rating Scale; BD, bipolar disorder; Wald, Wald statistic; df, degrees of freedom; $\mathrm{Cl}$, confidence interval.

individual(s) using substances. ${ }^{27}$ Accordingly, SUD in the family was another factor that our study identified as having a significant association with comorbid $\mathrm{AD}$ (odds ratio 2.18). Since there was, however, a very low number of patients having such a family history (four patients), generalization of this result should be done with caution.

Regarding the importance of depressive episode in BD, previous studies indicate that a greater number of depressive episodes is a risk factor for comorbid anxiety and mood disorders ${ }^{28}$ and that greater severity of depression is a risk factor for suicidality in BD. ${ }^{29}$ In addition, our study identified that a higher rating in depression scale (MADRS score) was another risk factor for $\mathrm{AD}$ comorbidity.

BD patients with comorbid AD frequently face multiple dimensions of physical and psychosocial problems, including sleep disorder, working impairments, and social functioning. ${ }^{8}$ Relatedly, we found that patients with comorbid $\mathrm{AD}$ possessed significant impairments in quality of life (SF-36 score) in almost all functional domains.

Importantly, the prevalence of current comorbid AD among our BD patients (12.5\%) was lower than in other studies; Das, ${ }^{6}$ Simon et al, ${ }^{9}$ and Gao et $\mathrm{al}^{30}$ reported $29.6 \%$, $30.5 \%$, and $74 \%$, respectively. Possible explanations for the lower prevalence include differences in the methods of diagnosis for comorbid AD (ie, the Thai MINI used in the present study versus the Hamilton Rating Scale for Anxiety used by Das) or the state of illness (ie, the majority of patients in the present study were already in the recovered state $[60.1 \%]$ ), so the therapeutic process leading to this inactive states might altogether obviate the current $\mathrm{AD}$ comorbidity. In support of this notion, our results showed that patients in an active state (eg, depressive or mixed or manic) possessed a higher rate of comorbid $\mathrm{AD}$ than those in a recovered state (16.0\% to $76.5 \%$ versus $8.5 \%$ ) (Table 1$)$. In addition, BD I was diagnosed in the majority (95.3\%) of the patients in the present study, which contrasts with Western reports, where prevalence of $\mathrm{BD}$ II is more frequent. ${ }^{31} \mathrm{BD} \mathrm{I}$ is reported to have a lower rate of $\mathrm{AD}$ comorbidity than
$\mathrm{BD}$ II,${ }^{32}$ and indeed the prevalence of $\mathrm{AD}$ comorbidity in $\mathrm{BD}$ can vary widely. ${ }^{33}$

As comorbid ADs have a critical impact on the course of $\mathrm{BD}$, for example, worse outcome regarding global and specific measures (namely, illness severity, proportion of the year spent psychologically ill or healthy), the risk factors identified in our report could alert clinicians to the presence of comorbid AD so that appropriate prevention and treatment can be promptly implemented.

\section{Conclusion}

The risk factors for comorbidity of $\mathrm{AD}$ in patients with $\mathrm{BD}$ were early-age onset of the disorder, SUD in the family, and greater intensity of the current depression. Later onset of $\mathrm{BD}$ seems to be protective as onset of this comorbidity falls by $5 \%$ with each passing year. The present study also underscores the seriousness of SUD within the family as an associated risk.

\section{Limitations}

The present study had some limitations: a) there was no control group; b) some demographic and course of illness data were subject to recall bias; c) the study was a substudy of the TBDR registry, which was designed to ascertain the mood patterns over a 1-year observational period, thus a more specific tool for anxiety assessment (ie, Hamilton Rating Scale for Anxiety) was not employed; d) many sites in the current study were in a psychiatric unit of a general hospital; and e) the risk factors for substance abuse can differ across cultures, and our sample was limited to the Thai population.

\section{Acknowledgments}

This study was supported by an unrestricted research grant from Sanofi-Aventis (Thailand) Ltd. The company did not have any influence on the study design, analysis plan, or preparation of the manuscript. Dr Panadda Klamsum of Sanofi-Aventis (Thailand) Ltd provided administrative support. Assistance with the statistical analysis was provided by statisticians from Sanofi-Aventis (Thailand) Ltd, namely, Ms Taweeporn Natesamroeng, Dr Suthat Chottanapund, and Dr Jaruek Charoensap.

We thank the Thai Bipolar Registry Study Group for its contributions in data collection. The group included Buddhachinnaraj Hospital: R Kanokvut, P Lengdee, and U Wilekha; Chachoengsao Hospital: W Pratoomsri; Galya Rajanagarindra Institute: W Thomkapanich; Institute of Aviation Medicine: P Onsiri; Khon Kaen Rajanagarindra Psychiatric Hospital: 
K Kittiwattanagul; King Chulalongkorn Memorial Hospital: P Lueboonthavatchai, C Roomruangwong, and S Tangwongchai; Maharaj Nakorn Chiang Mai Hospital: M Srisurapanont, and S Sutthijit; Phrae Hospital: S Tongprasert; Phramongkutklao Hospital: T Leelahanaj; Phrapokklao Hospital: S Sarakul; Prasrimahabhodhi Psychiatric Hospital: S Janthong and T Kongsuk; Rajavithi Hospital: P Thomyangkoon; Ramathibodi Hospital: P Ittasakul and R Kongsakon; Ratchaburi Hospital: S Limsiroratana and W Pattanakumjorn; Rayong Hospital: P Pattaranuthaporn; Siriraj Hospital: S Bussaratid; Somdet Chaopraya Institute of Psychiatry: W Chanakul and P Losatiankij; Srinagarind Hospital: S Paholpak; Srithanya Hospital: S Choovanichvong; Suansaranrom Psychiatric Hospital: S Joowong; Surin Hospital: K Surapongpiwattana and T Surapongpiwattana; Thammasat University Hospital: L Kosulwit; Udonthani Hospital: W Wongsuriyadech; Vachira Phuket Hospital: T Sumpatanarax. We also thank Mr Bryan Roderick Hamman for assistance with the English language presentation of the manuscript.

\section{Disclosure}

The following authors have received consulting fees, research grants, and/or honoraria from industry but none related to this work: Dr Suchat Paholpak from AstraZeneca, Janssen, Novartis, Pfizer, Sanofi-Aventis, and Thai Otsuka; Dr Ronnachai Kongsakon from AstraZeneca, Janssen, Novartis, Pfizer, Sanofi-Aventis, and Thai Otsuka; Dr Manit Srisurapanont from AstraZeneca, GlaxoSmithKline, Pfizer, Janssen, Johnson and Johnson, Lundbeck, Sanofi-Aventis, Servier, and Thai Otsuka. The other authors report no conflicts of interest in this work.

\section{References}

1. Sadock BJ, Sadock VA. Depression and bipolar disorder. In: Sadock BJ, Kaplan HI, Sadock VA, editors. Kaplan and Sadock's Synopsis of Psychiatry. 10th ed. Philadelphia, PA: Lippincott Williams \& Wilkin; 2007:527-562.

2. Siriwanarangsun P, Kongsuk T, Arunpongpaisan S, Kittirattanapaiboon P, Charatsingha A. Prevalence of mental disorders in Thailand: a national survey 2003. J Ment Health Thai. 2004;12(3):177-188.

3. Fagiolini A, Forgione R, Maccari M, et al. Prevalence, chronicity, burden and borders of bipolar disorder. J Affect Disord. 2013;148(2-3): 161-169.

4. Krishnan KR. Psychiatric and medical comorbidities of bipolar disorder. Psychosom Med. 2005;67(1):1-8.

5. Merikangas KR, Jin R, He JP, et al. Prevalence and correlates of bipolar spectrum disorder in the world mental health survey initiative. Arch Gen Psychiatry. 2011;68(3):241-251.

6. Das A. Anxiety disorders in bipolar I mania: prevalence, effect on illness severity, and treatment implications. Indian J Psychol Med. 2013;35(1): 53-59.

7. Albert U, Rosso G, Maina G, Bogetto F. Impact of anxiety disorder comorbidity on quality of life in euthymic bipolar disorder patients: differences between bipolar I and II subtypes. J Affect Disord. 2008;105(1-3):297-303.
8. Saunders EF, Fitzgerald KD, Zhang P, McInnis MG. Clinical features of bipolar disorder comorbid with anxiety disorders differ between men and women. Depress Anxiety. 2012;29(8):739-746.

9. Simon NM, Otto MW, Wisniewski SR, et al. Anxiety disorder comorbidity in bipolar disorder patients: data from the first 500 participants in the Systematic Treatment Enhancement Program for Bipolar Disorder (STEP-BD). Am J Psychiatry. 2004;161(12):2222-2229.

10. Boylan KR, Bieling PJ, Marriott M, Begin H, Young LT, MacQueen GM. Impact of comorbid anxiety disorders on outcome in a cohort of patients with bipolar disorder. J Clin Psychiatry. 2004;65(8): 1106-1113.

11. Hawke LD, Provencher MD, Parikh SV, Zagorski B. Comorbid anxiety disorders in Canadians with bipolar disorder: clinical characteristics and service use. Can J Psychiatry. 2013;58(7):393-401.

12. Stensland MD, Zhu B, Ascher-Svanum H, Ball DE. Costs associated with attempted suicide among individuals with bipolar disorder. JMent Health Policy Econ. 2010;13(2):87-92.

13. Tohen M, Greenfield SF, Weiss RD, Zarate CA, Vagge LM. The effect of comorbid substance use disorders on the course of bipolar disorder: a review. Harv Rev Psychiatry. 1998;6(3):133-141.

14. Antypa N, Antonioli M, Serretti A. Clinical, psychological and environmental predictors of prospective suicide events in patients with Bipolar Disorder. J Psychiatr Res. 2013;47(11):1800-1808.

15. Kenneson A, Funderburk JS, Maisto SA. Risk factors for secondary substance use disorders in people with childhood and adolescent-onset bipolar disorder: opportunities for prevention. Compr Psychiatry. 2013;54(5):439-446.

16. Meng X, D'Arcy C. Common and unique risk factors and comorbidity for 12-month mood and anxiety disorders among Canadians. Can J Psychiatry. 2012;57(8):479-487.

17. Leelahanaj T, Kongsakon R, Choovanichvong S, et al; Thai Bipolar Registry Study Group. Time to relapse and remission of bipolar disorder: findings from a 1-year prospective study in Thailand. Neuropsychiatr Dis Treat. 2013;9:1249-1256.

18. Udomratn P, Kittirattanapaiboon P. The Mini-International Neuropsychiatric Interview (Thai version). Bangkok: Graphic Hut; 2004.

19. Kongsakon R, Bhatanaprabhabhan D. Validity and reliability of the Young Mania Rating Scale: Thai version. J Med Assoc Thai. 2005;88(11):1598-1604.

20. Kongsakon R, Zartrugpak S, Rotjananirunkit A, Buranapichet U. The reliability and validity of the Thai version of Montgomery Asberg Depression Rating Scale (MADRS). J Psychiatr Assoc Thai. 2003;48: 211-219.

21. Spearing MK, Post RM, Leverich GS, Brandt D, Nolen W. Modification of the Clinical Global Impressions (CGI) Scale for use in bipolar illness (BP): the CGI-BP. Psychiatry Res. 1997;73(3):159-171.

22. Kongsakon R, Silpakit C. Thai version of the medical outcome study 36 item short form health survey (SF-36): an instrument for measuring clinical results in mental disorder patients. Rama Med J. 2000;23(1):8-19.

23. Chen YC, Kao CF, Lu MK, et al. The relationship of family characteristics and bipolar disorder using causal-pie models. Eur Psychiatry. 2014;29(1):36-43.

24. Etain B, Aas M, Andreassen OA, et al. Childhood trauma is associated with severe clinical characteristics of bipolar disorders. J Clin Psychiatry. 2013;74(10):991-998.

25. Azorin JM, Bellivier F, Kaladjian A, et al. Characteristics and profiles of bipolar I patients according to age-at-onset: findings from an admixture analysis. J Affect Disord. 2013;150(3):993-1000.

26. Lander L, Howsare J, Byrne M. The impact of substance use disorders on families and children: from theory to practice. Soc Work Public Health. 2013;28(3-4):194-205.

27. Yule AM, Wilens TE, Martelon MK, Simon A, Biederman J. Does exposure to parental substance use disorders increase substance use disorder risk in offspring? a 5-year follow-up study. Am J Addict. $2013 ; 22(5): 460-465$. 
28. Goes FS, McCusker MG, Bienvenu OJ, et al; National Institute of Mental Health Genetics Initiative Bipolar Disorder Consortium. Co-morbid anxiety disorders in bipolar disorder and major depression: familial aggregation and clinical characteristics of co-morbid panic disorder, social phobia, specific phobia and obsessive-compulsive disorder. Psychol Med. 2012;42(7):1449-1459.

29. Tijssen MJ, Van Os J, Wittchen HU, Lieb R, Beesdo K, Wichers M. Risk factors predicting onset and persistence of subthreshold expression of bipolar psychopathology among youth from the community. Acta Psychiatr Scand. 2010;122(3):255-266.

30. Gao K, Wang Z, Chen J, et al. Should an assessment of Axis I comorbidity be included in the initial diagnostic assessment of mood disorders? Role of QIDS-16-SR total score in predicting number of Axis I comorbidity. J Affect Disord. 2013;148(2-3):256-264.
31. Llorca PM, Camus V, Courtet P, Gourion D, Lukasiewicz M, Coulomb S. [Current status and management of patients with bipolar disorder in France: the MONTRA survey]. Encephale. 2013;39(3):212-223. French.

32. Chang YH, Chen SL, Chen SH, et al. Low anxiety disorder comorbidity rate in bipolar disorders in Han Chinese in Taiwan. Prog Neuropsychopharmacol Biol Psychiatry. 2012;36(1):194-197.

33. Levine J, Cole DP, Chengappa KN, Gershon S. Anxiety disorders and major depression, together or apart. Depress Anxiety. 2001;14(2): 94-104.

\section{Publish your work in this journal}

Neuropsychiatric Disease and Treatment is an international, peerreviewed journal of clinical therapeutics and pharmacology focusing on concise rapid reporting of clinical or pre-clinical studies on a range of neuropsychiatric and neurological disorders. This journal is indexed on PubMed Central, the 'PsycINFO' database and CAS.
The manuscript management system is completely online and includes a very quick and fair peer-review system, which is all easy to use. Visit http://www.dovepress.com/testimonials.php to read real quotes from published authors.

Submit your manuscript here: http://www.dovepress.com/neuropsychiatric-disease-and-treatment-journal 